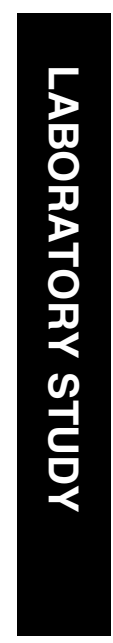

\title{
Longitudinal changes in refractive error of children with infantile esotropia
}

${ }^{1}$ Retina Foundation of the Southwest, Dallas, TX, USA

${ }^{2}$ Department of Ophthalmology, University of Texas Southwestern Medical Center, Dallas, TX, USA

${ }^{3}$ Directorate of Orthoptics and Vision Science, University of Liverpool, Liverpool, UK

Correspondence: EE Birch, Pediatric Eye Research Laboratory, Retina Foundation of the Southwest, 9900 North Central Expressway, Suite 400, Dallas, TX 75231, USA. Tel: + 12143633911 ext. 111;

Fax: +1 12143634538

E-mail: ebirch@

retinafoundation.org

Received: 20 May 2010 Accepted in revised form: 1 August 2010

Published online: 8 October 2010

Presented as a poster at the 2008 ARVO meeting in Ft. Lauderdale, FL

\begin{abstract}
Aim The aim of this study was to quantify changes in refractive status over time in children with infantile esotropia (ET) and to analyse a number of clinical factors associated with infantile ET to determine how they may affect emmetropisation.

Methods Longitudinal cycloplegic refraction data were collected for 5-12 years from 143 consecutive children enroled in a prospective study of infantile ET by 6 months of age. Changes in refractive error with age were summarised with descriptive statistics and the influence of amblyopia, undercorrection of hypermetropia, accommodation, and binocular factors on emmetropisation were evaluated by analysis of variance and $t$-tests.

Results Most had low to moderate hypermetropia on the initial visit $55 \%$ had $<+3.00 \mathrm{D}$ ). Although the initial refractive error is similar to normative data, the rapid decrease in hypermetropia that characterises normal development during the first 9 months of life is absent in children with infantile ET. After 9 months of age, children with infantile ET follow a developmental course, which is similar to the normative course; there is little change in hypermetropia during years 1-7, followed by a decline of approximately $-0.5 \mathrm{D} /$ year beginning at age 8 years. None of the clinical factors examined had a statistically significant effect on the course of refractive changes with age.

Conclusion Children with infantile ET exhibit a different pattern of refractive development than that seen in normative cohorts. The long-term changes in refraction observed in children with infantile ET suggest that there is a need for long-term clinical follow-up of these children. Eye (2010) 24, 1814-1821; doi:10.1038/eye.2010.129; published online 8 October 2010
\end{abstract}

EE Birch ${ }^{1,2}$, DR Stager $\mathrm{Sr}^{2}$, J Wang ${ }^{1}$ and A O'Connor ${ }^{3}$

Keywords: infantile esotropia; refractive error; emmetropisation; hypermetropia; accommodative esotropia; amblyopia

\section{Introduction}

Defective emmetropisation has been reported in children with strabismus ${ }^{1}$ and it has been hypothesised that the onset of strabismus results from persistent hypermetropia. ${ }^{2}$ Ingram reported that emmetropisation was defective in both eyes of more than $80 \%$ of children with either a microtropia or heterotropia, regardless of their early refractive status. ${ }^{1}$ However, because the follow-up period was limited to the first 3.5 years of life, it is not known whether the strabismus was associated with slower/delayed eye growth or whether the effect on eye growth persisted in the long term.

Prescribing glasses for hypermetropia in early childhood may impede emmetropisation, ${ }^{1}$ but in children with strabismus, emmetropisation may fail irrespective of refractive correction. ${ }^{3}$ This finding is somewhat difficult to interpret, though, because all cases of microtropia and heterotropia were considered together, and this prevents understanding of the impact of type of strabismus, visual acuity, and the level of binocular vision on emmetropisation. One study that did analyse esotropia (ET) and exotropia separately found an increase in the refractive error before the onset of ET, but no consistent relationship between refractive error and the onset of exotropia. ${ }^{2}$ However, the considerable variability in concomitance, constancy of the heterotropia, age of onset, and fusion/stereoacuity among children with ET makes it difficult to apply findings from this study to clinical care.

Concomitant ET has a bimodal age-of-onset distribution, with onset $<6$ months of age in 
about $40 \%$ and $18-48$ months in $60 \% .{ }^{4}$ One of the most common types of concomitant ET is infantile ET, with an incidence of $0.2-0.6 \%$ in the $\mathrm{UK}^{5-7}$ and US. ${ }^{8-11}$ Nearly, all children with infantile ET have surgery to align their eyes and over $80 \%$ require occlusion therapy and/or spectacle correction to treat amblyopia. ${ }^{12}$ Many require repeated interventions. In addition, sequelae of infantile ET include recurrent ET, consecutive exotropia, dissociated vertical deviation, and latent nystagmus. ${ }^{12-15}$ Recurrent ET is found in $60 \%$ of children who had surgery for infantile ET during the first 2 years of life even though $>80 \%$ have refractive error $<+3.00$ dioptre sphere (DS). It typically occurs after a 12 - to 24 -month period of post-surgical orthotropia and usually is accommodative or partially accommodative. ${ }^{16-20}$ It has been hypothesised that the poor binocular sensory outcome associated with infantile ET allows accommodative ET to develop at low to moderate levels of hypermetropia. ${ }^{17}$ Although the distribution of refractive errors in children with infantile ET has been described, with the most common refractive error in the range 0.00 to $+2.00 \mathrm{DS}(46.4-61 \%),{ }^{14,20-22}$ little is known about longitudinal changes in refractive status.

In children with low to moderate hypermetropia without strabismus, the bulk of emmetropisation occurs between 3 and 9 months of age. ${ }^{23-25}$ Predetermined genetic factors clearly play a role in this early period of eye growth. ${ }^{26}$ However, there is also evidence for active coordination between the optical and the structural development of the growing eye, which depends on the ability of the eye to detect hypermetropic defocus and respond to its refractive error, namely the amount of refractive change and axial growth during this early period is proportional to the initial amount of hypermetropia. ${ }^{24,27}$ The information provided to the developing eye by hypermetropic defocus will depend on both the underlying refractive error and on accommodation.

The aim of this study was to quantify changes in refractive status over time in children with infantile ET and to analyse a number of factors associated with infantile ET to determine how they may affect emmetropisation.

\section{Materials and methods}

\section{Participants}

Participants were 143 consecutive patients enroled in a prospective study of infantile ET at the time of diagnosis by 6 months of age. They were referred to the study by 16 Dallas-Fort Worth paediatric ophthalmologists. All were followed up for a minimum of 5 years. None of the patients had known developmental delay, concurrent ophthalmic, or systemic diseases. None of the children were born preterm ( $\leq 36$ weeks).

\section{Statement of ethics}

Informed consent was obtained from a parent before the infant's enrolment. This research protocol observed the tenets of the Declaration of Helsinki and was approved by the Institutional Review Board of the University of Texas Southwestern Medical Center.

\section{Patient care}

Patient care was at the discretion of the referring ophthalmologists, within the guidelines of the American Academy of Ophthalmology Preferred Practice Pattern: Esotropia and Exotropia. ${ }^{28}$ Briefly, initial management included spectacle correction of hypermetropia $\geq+3.00$ DS, prescribing the full cycloplegic retinoscopy findings (lesser amounts of hypermetropia were corrected at the ophthalmologist's discretion), and amblyopia treatment. Only after refractive and amblyopia treatment commenced, if needed, was surgery undertaken to correct ocular alignment. Postoperatively, glasses were prescribed whenever residual or recurrent ET was present and the hypermetropia was $\geq+3.00$ DS before 12 months, $\geq+2.00$ DS at $1-2$ years, and $\geq+1.5$ DS at $\geq 2$ years; glasses were prescribed for lesser amounts of hypermetropia at the ophthalmologist's discretion. Some of the referring ophthalmologists attempted to wean patients from spectacle wear gradually by initiating undercorrection by $0.50-1.00$ DS at 5-7 years of age and progressively decreasing the hypermetropic correction in 0.50 or $1.00 \mathrm{DS}$ increments at 6-month intervals. Hypermetropic correction was reduced only if the child maintained adequate alignment at distance and near with the current spectacle correction and remained aligned with the reduced correction when tested in the office with trial lenses. Compliance with glasses and amblyopia therapy was monitored by parent interview at the research laboratory visits. Perhaps because parents had voluntarily enroled their children as research participants in the study (located at a site separate from where the child received medical care), they were highly motivated to comply with treatment and generally reported excellent (>75\%) compliance.

\section{Onset and duration of esotropia}

The age at onset of ET was calculated based on information in medical records and a standardised parent questionnaire as described before. ${ }^{13}$ Age at alignment was defined as the age in months at which 
alignment within the 0 to $8^{\triangle}$ range was first achieved and maintained for at least 12 months (stable alignment). The duration of misalignment was calculated as the difference in months between the age at onset and the age at alignment.

\section{Refractive error}

Cycloplegic retinoscopy (1\% cyclopentolate) was performed by the referring paediatric ophthalmologists as part of routine medical care. Data were recorded in the traditional format of sphere $(S)$, plus cylinder $(C)$, and axis $(\alpha)$. These raw data were converted into power vector components: ${ }^{29} M$ (spherical equivalent), $J_{0}$ (positive $J_{0}$ indicates with-the-rule astigmatism; negative $J_{0}$ indicates against-the-rule astigmatism), and $J_{45}$ (oblique astigmatism):

$$
\begin{aligned}
& M=S+\frac{C}{2} \\
& J_{0}=\left(-\frac{C}{2}\right) \cos 2 \alpha \\
& J_{45}=\left(-\frac{C}{2}\right) \sin 2 \alpha
\end{aligned}
$$

Although standard notation is limited to reports of spherical equivalent and cylinder power without regard to precise axis, power vector notation can be used to track changes in refractive error with age as simple, linear differences between independent vector components.

\section{Statistical methods}

With the exception of anisometropia, all refractive error data are reported for right eyes only. Descriptive statistics are presented as mean $\pm S D$, except for angle of deviation, which is reported as the median \pm interquartile interval because prism measurement is on a non-interval scale. Change in refraction over time was calculated as the difference in refraction at the last visit in the 5- to 7-year age interval and the last visit in the 8- to 12-year age interval divided by the number of years between the two visits (DS/year). $t$-tests were used for two-group comparisons and one-way analysis of variances for comparisons among multiple groups. Two-way analysis of variance was used to evaluate the interaction between change in refractive error by year and age at which amblyopia was present (never, infantile, age $2-5$ years, persistent long-term). Linear regression was used to define the relationship between initial refractive error and refractive error at 5-7, 8-10, and 11-12 years.

\section{Results \\ Clinical factors}

The mean age $( \pm S D)$ at onset of the ET was $2.8 \pm 1.3$ months. A total of $86(60 \%)$ of the participants had onset at age 2 months, $29(20 \%)$ at age 3 months, $12(8 \%)$ at age 4 months, $9(6 \%)$ at age 5 months, and $7(5 \%)$ at age 6 months. The mean age at initial visit was $4.5 \pm 1.7$ months. The median angle of ET at the initial visit, measured to the nearest $5^{\Delta}$ was $45^{\Delta}\left(\mathrm{IQR} \pm 10^{\Delta}\right)$.

A total of $13(9 \%)$ of the participants had resolution of their ET before 12 months of age with $(n=9$, ET only present without glasses) or without ( $n=4$, no ET; excluded from the analysis) spectacle correction. The remaining $130(91 \%)$ participants had surgery at a mean age of $9.9 \pm 5.6$ months. The age at initial surgery was $\leq 12$ months for $114(80 \%)$ participants, $12-24$ months for $9(6 \%)$ participants, and $>24$ months for 7 (5\%) participants. Among the 114 participants who had surgery before age 12 months, 97 were aligned within $8^{\triangle}$ postoperatively, 3 improved to $<8^{\triangle}$ with spectacle correction, and 14 had residual ET $\geq 10^{\triangle}$ postoperatively (11 of these 14 had a second surgery at age $10.4 \pm 1.9$ months). Among the 16 participants who had surgery after 12 months of age, 15 were aligned within $8^{\triangle}$ postoperatively and 1 improved to $\leq 8^{\triangle}$ with spectacle correction. During the follow-up period of 5-12 years, $57 \%(n=82)$ required additional surgery for recurrent ET ( $n=17$; age at surgery $=43.5 \pm 35.9$ months), for consecutive exotropia $(n=29$; age at surgery $=57.7 \pm 36.2$ months), or for dissociated vertical deviation,

hypertropia, or oblique muscle overaction ( $n=53$; age at surgery $=40.5 \pm 21.6$ months); note that some children had more than one type of surgery.

The mean duration of ET before attaining stable alignment ( $\leq 8^{\triangle}$ for a minimum of 12 months) was $5.4 \pm 8.3$ months. A total of $72(50 \%)$ of the participants had duration of $\leq 3$ months and $71(50 \%)$ had duration of 4 months or more. Mean age at follow-up was $8.7 \pm 3.2$ years (range $5-12$ years).

In all, 82 (57\%) participants were classified as amblyopic by fixation preference testing at the initial visit, either by absence of steady, central fixation by one eye $(n=12 ; 8 \%)$ or failure to maintain fixation through a blink with one eye $(n=70 ; 49 \%)$. These participants were treated for amblyopia with occlusion therapy of $0.5-4 \mathrm{~h} /$ day for 1-3 months before surgery. Overall, 55 (38\%) participants were never found to be amblyopic during the 5-12 year follow-up period, 54 (38\%) participants had only one episode of amblyopia treatment (30 before 12 months of age, 12 at 2-5 years of age, 12 at $>5$ years of age), and 18 (13\%) had long-term amblyopia that persisted beyond 7 years of age despite treatment with occlusion therapy and/or atropine. 


\section{Refractive error on the initial visit}

On the initial visit, most infants with infantile ET had low to moderate hypermetropic refractive errors; $55 \%$ had a spherical equivalent of $<+3.00 \mathrm{DS}, 27 \%$ had a spherical equivalent of +3.00 to +4.99 DS, and only $19(13 \%)$ had a spherical equivalent of $\geq+5.00$ DS. Eight $(6 \%)$ had a myopic spherical equivalent. Anisometropia $\geq 1.00$ DS was rare $(n=13 ; 9 \%)$ but astigmatism $\geq 1.00 \mathrm{DC}$ was common $(n=52 ; 36 \%$, including $15 \%$ WTR, $10 \%$ ATR, and $10 \%$ oblique astigmatism). On the initial visit, 57 $(40 \%)$ children had refractive error sufficient to require spectacle correction according to the American Academy of Ophthalmology guidelines described previously. ${ }^{28}$

A total of 40 of the 57 infants were prescribed glasses on the initial visit. Seven infants who were $\leq 3$ months of age at the time of the initial visit and/or presented with a variable angle of deviation were prescribed glasses at the second visit, 2-8 weeks later. The remaining 10 infants either were not prescribed glasses (ET $\geq 50^{\triangle}$ with $\leq+3.50 \mathrm{DS}$ and anisometropia $<1.00 \mathrm{DS} ; n=8$ ) or the parents refused treatment with glasses $(n=2)$.

On the basis of power vector analyses of the raw cycloplegic refraction data, mean spherical error $(M)$ at the initial visit was $+2.54 \pm 1.83$ DS for right eyes and $+2.55 \pm 1.82 \mathrm{DS}$ for left eyes. Mean astigmatic error was negligible $\left(J_{0}=0.05 \pm 0.37 \mathrm{DC} ; J_{45}=-0.12 \pm 0.26 \mathrm{DC}\right)$. Mean anisometropia $\left(\left|M_{\text {right }}-M_{\text {left }}\right|\right)$ was $0.28 \pm 0.60$ DS.

\section{Longitudinal changes in refractive error}

Children with infantile ET remained moderately hypermetropic through age 7 years (at 7 years, $M=+3.18 \pm 1.78$ DS; Figure 1). Most children had either no change or an increase in the amount of hypermetropia at 5-7 years compared with their initial visit; only $28 \%$ had a decrease of $\geq 0.5$ DS over this age range. After age 7 years, refractive error decreased

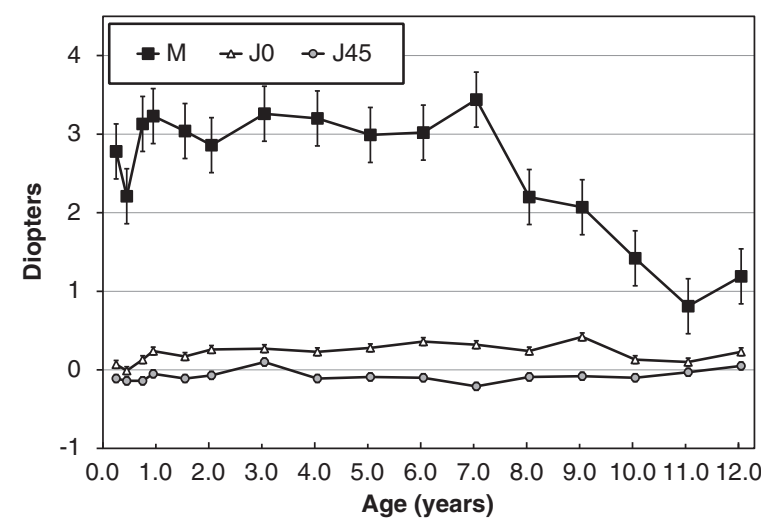

Figure 1 Mean \pm SE right eye refractive error as a function of age expressed in power vector notation (see text for details). by approximately $-0.50 \mathrm{DS} /$ year, so that at age 11-12 years $M=+1.00 \mathrm{D} \pm 2.22 \mathrm{DS}$.

Half $(50 \%)$ of the children had a decrease in the amount of hypermetropia at 8-10 years compared with their initial visit and $71 \%$ had a decrease in the amount of hypermetropia at 11-12 years compared with their initial visit. Children with more hypermetropia on the initial visit showed larger decreases in hypermetropia during follow-up (Figure 2). Nonetheless, children who had $\geq+5.00$ on their initial visit $(n=19)$ had a mean decrease of only $1.1 \pm 2.4$ DS by $8-10$ years ( $\sim 0.5 \mathrm{DS} /$ year) and all the 19 children remained hypermetropic at the final visit.

Mean astigmatic error remained negligible throughout age 7 years $\left(J_{0}=0.27 \pm 0.47 \mathrm{DC} ; J_{45}=-0.07 \pm 0.26 \mathrm{DC}\right.$; Figure 1). The prevalence of anisometropia remained approximately constant throughout follow-up (7-11\%). Most anisometropia that was present during infancy (9 of 13 cases; 69\%; range of anisometropia on initial visit: 1.00-3.75 DS) resolved during follow-up, but new cases developed, including 10 new cases of anisometropia with onset $\geq 5$ years of age (range of anisometropia on most recent visit: 1.00-2.25 DS).

\section{Comparison to normal growth of the eye}

Compared with the normal rapid decline in hypermetropia during the first 9-12 months of life reported in the literature, ${ }^{23,25,30,31}$ children with infantile ET showed little change in hypermetropia during

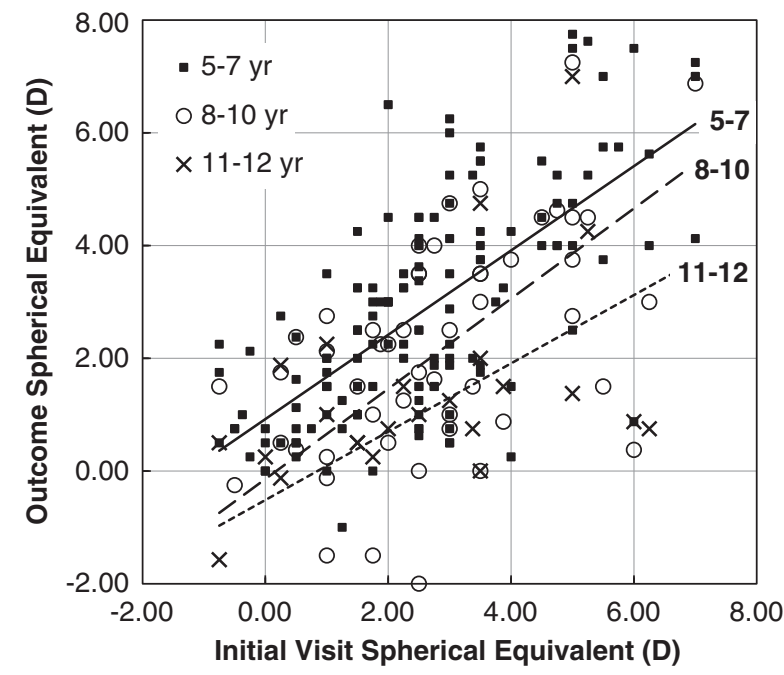

Figure 2 Spherical equivalent of the right eye at the 5-7, 8-10, and 11-12 year outcome visits related to spherical equivalent at the initial visit. Lines show the best-fit linear regression for each outcome visit on initial visit refraction. The best-fit lines for regression of outcome refractive error on initial refractive error was $y=0.75 x+0.92(r=0.67)$ for outcome at $5-7$ years, $y=0.80 x-0.14 \quad(r=0.61)$ for outcome at $8-10$ years, and $y=0.61 x-0.52(r=0.56)$ for outcome at $11-12$ years. 


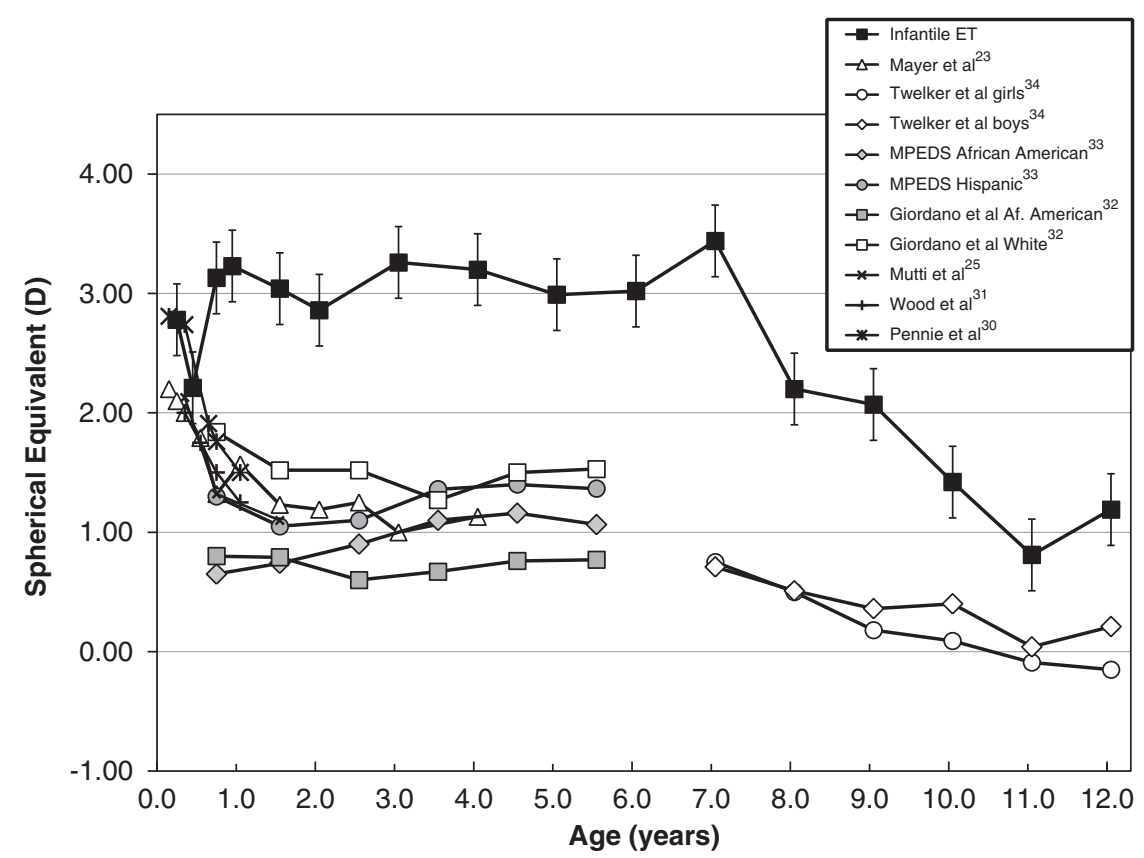

Figure 3 Mean \pm SE spherical error $(M)$ of right eyes of children with infantile ET (current study) and in previously published normative data. ${ }^{23,25,30-34}$

infancy (Figure 3). On the other hand, the $0.50 \mathrm{DS} /$ year myopic trend that was present in children with infantile ET between 7-12 years of age is similar to normative data. ${ }^{32-34}$

\section{Amblyopia}

Similar changes in refractive error with age were found for subgroups of patients with infantile ET who were never amblyopic, were diagnosed with amblyopia only during infancy (by fixation preference), or had short-term amblyopia at age 2-5 years (Figure 4 ). All subgroups remained moderately hypermetropic through age 7 years and, after age 7 years, refractive error decreased by approximately $-0.50 \mathrm{DS} /$ year. For the subgroup of children who had persistent amblyopia, which was present from age 5 years until the final visit, there was a suggestion of a smaller total change or slower rate of change with age after 7 years of age, averaging about $-0.25 \mathrm{DS} /$ year but this was not statistically significant (subgroup $\times$ age interaction for ages $5-12$ years:

$\left.F_{6,117}=0.38 ; P=0.68\right)$.

\section{Weaning from spectacles}

In addition to the 47 children who received spectacle correction for hypermetropia at the first or second visit, an additional 35 began spectacle wear postoperatively (beginning at 1.5-4 years of age) for a total of 82 children with long-term spectacle wear. Of these 82 children, 46 had an attempt to wean from spectacle wear gradually by initiating undercorrection by 0.50 to $1.00 \mathrm{DS}$ at

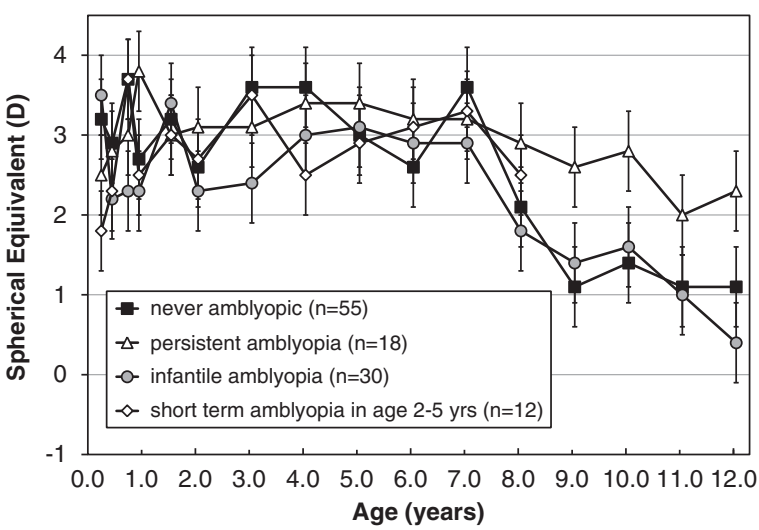

Figure 4 Mean $\pm S E$ spherical error $(M)$ for right eyes of children with infantile ET, who were never amblyopic, were diagnosed with amblyopia only during infancy (by fixation preference), had short-term amblyopia at age 2-5 years, or who had amblyopia that persisted beyond 5 years of age despite long-term and/or multiple attempts to treat.

5-7 years of age and progressively decreasing the hypermetropic correction in 0.50 DS or 1.00 DS increments at every 6-month intervals as long as the child was able to maintain adequate alignment at distance and near with the reduced power. Figure 5 shows the course of refractive changes in the group that had weaning attempted and in the group that did not. The refractive changes as a function of age were similar in both groups. In the weaning group, $32 \%$ of the children with an initial refractive error $>+3.00$ DS had a final refractive error of 0.00 to +1.00 DS, which was not statistically significantly different from the prevalence of $25 \%$ in the no weaning group. 


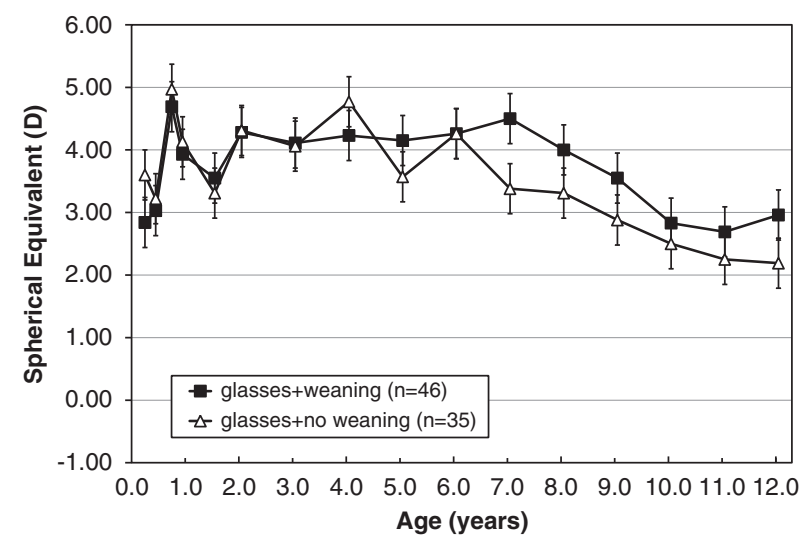

Figure 5 Mean \pm SE spherical error $(M)$ for right eyes of children with infantile ET who wore hypermetropic spectacle correction, with an attempt to wean with progressive undercorrection beginning at 5-7 years of age or without an attempt to wean.

\section{Accommodation}

Children with non-accommodative infantile ET, with initial visit refractive error ranging from -0.75 to +3.00 DS, had a slight increase in hypermetropia during the first 5 years of life $(+0.5 \pm 0.3$ DS $)$ followed by a progressive decrease in hypermetropia $(0.50 \pm 0.41 \mathrm{DS} /$ year) during years 8-12. Children with infantile accommodative ET had higher refractive errors on their initial visit (range +3.00 to $+7.00 \mathrm{DS}$ ) and showed little change during the first 5 years, but experienced similar decreases in hypermetropia (0.61 \pm 0.32 DS/year) during years 8-12. Children with partially accommodative ET experienced a mean decrease of $0.38 \pm 0.66 \mathrm{DS} /$ year. There were no statistically significant differences among nonaccommodative, accommodative, and partially accommodative groups in the rate of change in refractive error during years $8-12\left(F_{2,142}=0.92, P=0.40\right)$.

\section{Binocular factors}

Children with anisometropia on the initial visit had statistically significantly more hypermetropia than children without anisometropia in the more hypermetropic eye $(+3.52 \pm 1.81$ vs $+2.52 \pm 1.83 \mathrm{DS}$, respectively, $t_{141}=2.07, P=0.04$ ) and trended toward statistically significantly less hypermetropia than children without anisometropia in the less hypermetropic eye $(+1.69 \pm 1.81$ vs $+2.52 \pm 1.83 \mathrm{DS}$; respectively, $\left.t_{141}=1.80 ; P=0.07\right)$. Anisometropic children showed statistically significant decreases in hypermetropia during follow-up and, in 9 of 13 (69\%), loss of anisometropia.

Children with normal stereoacuity at $\geq 5$ years of age ( $\leq 60$ arc sec on the Randot preschool stereoacuity test) had statistically significantly more hypermetropia at their initial visit than those with reduced $(3.95 \pm 1.99$ vs $2.25 \pm 1.78 \mathrm{DS}$, respectively, $t_{60}=3.13, P=0.003$ ) or nil stereoacuity ( $3.95 \pm 1.99$ vs $2.43 \pm 1.84 \mathrm{DS}$, respectively, $\left.t_{74}=2.78, P=0.007\right)$ and at their $5-7$ year visit $(3.97 \pm 1.47$ vs $2.67 \pm 1.88 \mathrm{DS}$, respectively; $t_{60}=2.13, P=0.04$ and $3.97 \pm 1.99$ vs $2.69 \pm 1.93$ DS, respectively, $t_{74}=2.15$, $P=0.04$ ). Beyond 7 years of age, there were no statistically significant differences.

Regardless of motor outcome following the initial surgery or duration of ET before stable alignment, a similar trend in refractive development was found, with stable or slightly increasing hypermetropia through age 7 years followed by progressive decreases in hypermetropia through age 12 years.

\section{Discussion}

Most children with infantile ET had low to moderate hypermetropia on the initial visit before 6 months of age, and the hypermetropia either remained stable or increased through at least age 5 years. Beginning at age 8 years and continuing through age 12 years, hypermetropia decreased by $0.5 \mathrm{DS} /$ year on average. The pattern of refractive development in children with infantile ET was distinctly different from that previously reported for normative cohorts of children. ${ }^{23-25,30-35}$ In normative cohorts, children typically undergo a rapid decrease in hypermetropic refractive error between 3 and 9 months, followed by long period of near-emmetropia from 1-5 years of age. On the other hand, after age 5 years, the children with infantile ET are similar to the reported normative cohorts, in that both show myopic shifts of -0.5 DS/year after 7 years of age and those with the highest initial amounts of hypermetropia show greater myopic shift.

Children with an accommodative ET show a similar trend of little change or slight increase in hypermetropia before 7 years, then decreasing hypermetropia after age 7 years; ${ }^{36-39}$ however, they show slower rate of change (0.11-0.18 DS/year) in hypermetropia than our infantile ET cohort. ${ }^{36-39}$ This is surprising because, at least in infancy, the rate of change is correlated with the degree of refractive error ${ }^{25,27}$ and the accommodative ET cohorts have higher initial hypermetropia than our infantile ET cohort. ${ }^{36-39}$ Within our cohort of infantile ET, even those with high hypermetropia on the initial visit ( $\geq+5.00 \mathrm{DS}$ ) had approximately the same $0.5 \mathrm{DS} /$ year rate of decrease in hypermetropia after age 7 years.

There is some evidence that amblyopia may affect emmetropisation in strabismic amblyopia and moderate to high hypermetropia. ${ }^{40}$ However, in agreement with Rutstein and Corliss, ${ }^{41}$ we found that amblyopia had no statistically significant impact on the change in 
hypermetropia over time in children with strabismic amblyopia. Our data were presented for right eyes, regardless of which eye was amblyopic, but re-analysis of amblyopic and fellow eye separately yielded similar results. Taken together, these two studies suggest that amblyopia is not a major factor in refractive change over the first 12 years of life in strabismic amblyopia with low to moderate hypermetropia; whether this finding can be generalised to other forms of strabismic amblyopia is unknown.

On the basis of evidence that infant rhesus monkeys who wore plus lenses become more hypermetropic, ${ }^{42,43}$ it has been suggested that providing the full hypermetropic spectacle correction may interfere with emmetropisation. ${ }^{39}$ Our weaning data (Figure 5) do not support this hypothesis. There were no statistically significant differences among patients with nonaccommodative ET, accommodative ET, and partially accommodative ET groups in the lack of change in hypermetropia during the first 5-7 years of life or in the rate of change in refractive error during years 8-12. In addition, although the success of undercorrection of hypermetropia in children with acquired accommodative ET in reducing hypermetropia has been reported to be $60 \%$ in a small series of 10 patients, ${ }^{37}$ we found that undercorrection of hypermetropia did not affect the rate of decrease in hypermetropia that began after 7 years of age nor did weaning affect the proportion of children with initial refraction $>+3.00$ DS, who achieved a final refraction of 0.00 to $+1.00 \mathrm{DS}$. This result is similar to a recent study of 285 children with accommodative ET, in which weaning had no effect on rate of decrease of hypermetropia after age 7 years. ${ }^{36}$ None of the factors associated with binocular function (anisometropia, stereoacuity, duration of misalignment before achievement of stable alignment) affected the developmental changes in refractive error in children with infantile ET.

In summary, children with infantile ET exhibit a different pattern of refractive development in comparison to normative cohorts. During the first 9 months, the axial growth of the eye normally reduces hypermetropia because its dioptric effects exceed the effects of losses in corneal and lens power. ${ }^{24,44}$ Whether the different pattern of refractive development observed in children with infantile ET is owing to differences in maturation of axial length, cornea, and/or lens is unknown. The decline of hypermetropia at a rate of approximately $-0.5 \mathrm{DS} /$ year beginning at age 8 years, whether or not the child wore full spectacle correction of hypermetropia, suggests that spectacle wear does not cause disadvantage to the growing eye of children with infantile ET. Owing to changes in refraction after age 7 years, there is a need for long-term follow-up of these children.

\section{Summary}

\section{What was known before}

- In children with low to moderate hypermetropia without strabismus, the bulk of emmetropisation occurs between 3 and 9 months of age. Predetermined genetic factors clearly play a role in this early period of eye growth, but there is also evidence for active coordination between the optical and structural development of the growing eye that depends on the ability of the eye to detect hypermetropic defocus. Little is known about emmetropisation in children with infantile esotropia or the clinical factors associated with infantile ET that may affect emmetropisation.

What this study adds

- Most children with infantile ET had low to moderate hypermetropia on the initial visit prior to 6 months of age, and the hypermetropia either remained stable or increased through at least age 5 years. Beginning at age 8 years and continuing through age 12 years, hypermetropia decreased by $0.5 \mathrm{D} /$ year on average. The pattern of refractive development in children with infantile ET was distinctly different from that previously reported for normative cohorts of children. The decline of hypermetropia at the rate of approximately $-0.5 \mathrm{D} /$ year beginning at age 8 years, whether or not the child wore full spectacle correction of hypermetropia, suggests that spectacle wear does not disadvantage the growing eye of children with infantile ET. Due to changes in refraction after age 7 years, there is a need for long-term follow-up of these children.

\section{Conflict of interest}

The authors declare no conflict of interest.

\section{Acknowledgements}

This study was supported by a grant from the National Eye Institute (EY05236). Christina Cheng assisted with database design and data entry.

\section{References}

1 Ingram RM, Gill LE, Lambert TW. Emmetropisation in normal and strabismic children and the associated changes of anisometropia. Strabismus 2003; 11: 71-84.

2 Abrahamsson M, Fabian G, Sjostrand J. Refraction changes in children developing convergent or divergent strabismus. Br J Ophthalmol 1992; 76: 723-727.

3 Ingram RM, Gill LE, Lambert TW. Effect of spectacles on changes of spherical hypermetropia in infants who did, and did not, have strabismus. Br J Ophthalmol 2000; 84: 324-326.

4 Tychsen L. Visual cortex mechanisms of strabismus: development and maldevelopment. In: Lorenz B, Brodsky M (eds). Pediatric Ophthalmology, Neuro-Ophthalmology, Genetics. Springer-Verlag: Heidelberg, 2010, pp 41-58.

5 Anker S, Atkinson J, Braddick O, Ehrlich D, Hartley T, Nardini $\mathrm{M}$ et al. Identification of infants with significant refractive error and strabismus in a population screening program using noncycloplegic videorefraction and 
orthoptic examination. Invest Ophthalmol Vis Sci 2003; 44: 497-504.

6 Williams C, Northstone K, Harrad RA, Sparrow JM, Harvey I. Amblyopia treatment outcomes after screening before or at age 3 years: follow up from randomised trial. Br Med J 2002; 324: 1549.

7 Williams C, Northstone K, Howard M, Harvey I, Harrad RA, Sparrow JM. Prevalence and risk factors for common vision problems in children: data from the ALSPAC study. Br J Ophthalmol 2008; 92: 959-964.

8 Friedman DS, Repka MX, Katz J, Giordano L, Ibironke J, Hawse $\mathrm{P}$ et al. Prevalence of amblyopia and strabismus in white and African American children aged 6 through 71 months the Baltimore Pediatric Eye Disease Study. Ophthalmology 2009; 116: 2128-2134, e2121-e2122.

9 Greenberg AE, Mohney BG, Diehl NN, Burke JP. Incidence and types of childhood esotropia: a population-based study. Ophthalmology 2007; 114: 170-174.

10 Louwagie CR, Diehl NN, Greenberg AE, Mohney BG. Is the incidence of infantile esotropia declining?: a populationbased study from Olmsted County, Minnesota, 1965 to 1994. Arch Ophthalmol 2009; 127: 200-203.

11 Multi-ethnic Pediatric Eye Disease Study Group. Prevalence of amblyopia and strabismus in African American and Hispanic children ages 6 to 72 months the multi-ethnic pediatric eye disease study. Ophthalmology 2008; 115: 1229-1236, e1221.

12 Birch EE, Stager Sr DR, Berry P, Leffler J. Stereopsis and long-term stability of alignment in esotropia. J AAPOS 2004; 8: 146-150.

13 Birch EE, Fawcett S, Stager DR. Why does early surgical alignment improve stereoacuity outcomes in infantile esotropia. J AAPOS 2000; 4: 10-14.

14 Birch EE, Felius J, Stager Sr DR, Weakley Jr DR, Bosworth RG. Pre-operative stability of infantile esotropia and postoperative outcome. Am J Ophthalmol 2004; 138: 1003-1009.

15 Birch EE, Stager Sr DR. Long-term motor and sensory outcomes after early surgery for infantile esotropia. I AAPOS 2006; 10: 409-413.

16 Baker JD, DeYoung-Smith M. Accommodative esotropia following surgical correction of congenital esotropia, frequency and characteristics. Graefes Arch Clin Exp Ophthalmol 1988; 226: 175-177.

17 Birch EE, Fawcett SL, Stager Sr DR. Risk factors for the development of accommodative esotropia following treatment for infantile esotropia. J AAPOS 2002; 6: 174-181.

18 Hiles DA, Watson BA, Biglan AW. Characteristics of infantile esotropia following early bimedial rectus recession. Arch Ophthalmol 1980; 98: 697-703.

19 Raab EL. Etiologic factors in accommodative esodeviation. Trans Am Ophthalmol Soc 1982; 80: 657-694.

20 Robb RM, Rodier DW. The broad clinical spectrum of early infantile esotropia. Trans Am Ophthalmol Soc 1986; 84: 103-116.

21 Birch EE, Stager DR, Wright K, Beck R. The natural history of infantile esotropia during the first six months of life. J AAPOS 1998; 2: 325-328.

22 Costenbader FD. Essential infantile esotropia. Trans Am Ophthalmol Soc 1961; 59: 397.

23 Mayer DL, Hansen RM, Moore BD, Kim S, Fulton AB. Cycloplegic refractions in healthy children aged 1 through 48 months. Arch Ophthalmol 2001; 119: 1625-1628.

24 Mutti DO, Mitchell GL, Jones LA, Friedman NE, Frane SL, Lin WK et al. Axial growth and changes in lenticular and corneal power during emmetropization in infants. Invest Ophthalmol Vis Sci 2005; 46: 3074-3080.

25 Mutti DO, Mitchell GL, Jones LA, Friedman NE, Frane SL, Lin WK et al. Accommodation, acuity, and their relationship to emmetropization in infants. Optom Vis Sci 2009; 86: 666-676.

26 Tarczy-Hornoch K. The epidemiology of early childhood hyperopia. Optom Vis Sci 2007; 84: 115-123.

27 Saunders KJ. Early refractive development in humans. Surv Ophthalmol 1995; 40: 207-216.

28 American Academy of Ophthalmology. Preferred Practice Pattern: Esotropia and Exotropia. 2007.

29 Thibos LN, Wheeler W, Horner D. Power vectors: an application of Fourier analysis to the description and statistical analysis of refractive error. Optom Vis Sci 1997; 74: 367-375.

30 Pennie FC, Wood IC, Olsen C, White S, Charman WN. A longitudinal study of the biometric and refractive changes in full-term infants during the first year of life. Vision Res 2001; 41: 2799-2810.

31 Wood IC, Hodi S, Morgan L. Longitudinal change of refractive error in infants during the first year of life. Eye 1995; 9(Part 5): 551-557.

32 Giordano L, Friedman DS, Repka MX, Katz J, Ibironke J, Hawes $\mathrm{P}$ et al. Prevalence of refractive error among preschool children in an urban population: the Baltimore Pediatric Eye Disease Study. Ophthalmology 2009; 116: 739-746, e731-e734.

33 Multi-Ethnic Pediatric Eye Disease Study Group. Prevalence of myopia and hyperopia in 6- to 72-month-old African American and Hispanic children: the multi-ethnic pediatric eye disease study. Ophthalmology 2010; 117: 140-147, e143.

34 Twelker JD, Mitchell GL, Messer DH, Bhakta R, Jones LA, Mutti DO et al. Children's ocular components and age, gender, and ethnicity. Optom Vis Sci 2009; 86: 918-935.

35 Twelker JD, Mutti DO. Retinoscopy in infants using a near noncycloplegic technique, cycloplegia with tropicamide $1 \%$, and cycloplegia with cyclopentolate $1 \%$. Optom Vis Sci 2001; 78: 215-222.

36 Black BC. The influence of refractive error management on the natural history and treatment outcome of accommodative esotropia (an American Ophthalmological Society thesis). Trans Am Ophthalmol Soc 2006; 104: 303-321.

37 Hutcheson KA, Ellish NJ, Lambert SR. Weaning children with accommodative esotropia out of spectacles: a pilot study. Br J Ophthalmol 2003; 87: 4-7.

38 Raab EL. Persisting accommodative esotropia. Trans Am Ophthalmol Soc 1986; 84: 94-102.

39 Repka MX, Wellish K, Wisnicki HJ. Changes in the refractive error of 94 spectacle-treated patients with acquired accommodative esotropia. Binocul Vis 1989; 4: 5-21.

40 Lepard CW. Comparative changes in the error of refraction between fixing and amblyopic eyes during growth and development. Am J Ophthalmol 1975; 80: 485-490.

41 Rutstein RP, Corliss DA. Long-term changes in visual acuity and refractive error in amblyopes. Optom Vis Sci 2004; 81: 510-515.

42 Smith EL, Hung LF, Harwerth RS. Effects of optically induced blur on the refractive status of young monkeys. Vision Res 1994; 34: 293-301.

43 Smith EL, Hung LF, Harwerth RS. Developmental visual system anomalies and the limits of emmetropization. Ophthalmic Physiol Opt 1999; 19: 90-102.

44 Jones LA, Mitchell GL, Mutti DO, Hayes JR, Moeschberger ML, Zadnik K. Comparison of ocular component growth curves among refractive error groups in children. Invest Ophthalmol Vis Sci 2005; 46: 2317-2327. 